\title{
ANALISIS FAKTOR YANG MEMENGARUHI NIAT PENGGUNA PADA GOPAY DENGAN PENDEKATAN TECHNOLOGY ACCEPTANCE MODEL
}

\author{
Priska Liliani \\ Universitas Bina Nusantara \\ priscaaliliani19@gmail.com
}

\begin{abstract}
The purpose of this research is determine the factors that influence user intentions on gopay and determine the factors that most influence user intentions on gopay. This research was conducted on 50 respondents in Tangerang and Jakarta who have experience using the gopay application. User intention factors that will be carried out in the research include Applicable, Flexible, Controllable, Effectiveness, Usefulness, Benefits, Compatibility, Recommendation, Reuse Intention, and Pay More. With the factor analysis test, a group of factors is formed which is the TAM factor. Using ranking values from factor analysis can identify the factors that most influence the use of gopay.
\end{abstract}

Keywords: Factor Analysis, Consumer Behaviour, Intention to Use, Technology Acceptance Model, Mobile Payment, Gopay

\section{PENDAHULUAN}

Pada umunya masyarakat khususnya di Indonesia akan menggunakan uang untuk alat pembayaran untuk membeli barang atau jasa. Perkembangan dengan pesat tersebut, cara pembayaranpun sekarang ini sudah berubah dengan elektronik agar dapat mengurangi penggunaan kertas, salah satunya menggunakan sistem pembayaran secara elektronik (e-money). E-money atau electronic money pada umumnya sudah banyak mendengar di mata masyarakat. Praktek E-money pada dasarnya disetor terlebih dahulu oleh pemegang, setelah itu nilai uang tersebut nantinya akan disimpan dalam sebuah chip. Sekarang ini e-money penggunaannya dapat dilakukan untuk membayar barang atau jasa. Di Indonesia, nilai transaksi e-money menunjukkan ketidakstabilan selama 6 bulan terakhir di tahun 2020 hal ini tergambarkan pada table di bawah ini : 
Tabel 1 Jumlah Nominal Transaksi e-money Januari-Juni 2020

\begin{tabular}{c|c} 
Tahun 2020 & Nominal Transaksi E-money (Juta Rupiah) \\
Januari & $313,785,298$ \\
Februari & $319,294,014$ \\
Maret & $330,391,364$ \\
April & 412.055 .870 \\
Mei & $346,881,617$ \\
Juni & $353,587,670$ \\
\hline
\end{tabular}

Sumber : Bank Indonesia

Berdasarkan tabel di atas hal ini menunjukan bahwa dari bulan januari hingga maret mengalami kenaikan, sedangkan untuk bulan april hingga juni mengalamipenurunan dramatis. Di zaman globalisasi pada saat seperti ini, masyarakat di Indonesia sebenarnya sudah sangat dimudahkan dengan pelayanan e-money untuk mempermudah masyarakat dalam kegiatan bertransaksi, dan pada saat ini pun e-money yang terjadi pada saat inipun dapat diakses melalui ponsel pintar yang artinya pengguna $e$-money tidak lagi memerlukan personal computer untuk dapat menikmati layanan e-money, dan layanan e-money juga sudah didukung dengan penggunaan teknologi seperti NFC (Near Field Communication) yang di mana teknologi tersebut dilakukan dengan pemindahan data tanpa kabel dalam jarak dekat dan dapat menghubungkan dari perangkat elektronik dengan perangkat elektronik lainnya yang apabila memungkinkan mempunyai teknologi NFC. NFC sekarang ini merupakan sebagai sebuah solusi pembayaran yang praktis mulai dari pembelian barang, dompet digital (e-wallet) hingga pembelian tiket. $e$ money pun sekarang ini dapat digunakan dengan mobile phone, peranan tersebutpun sudah meningkat dari tahun ke tahun. Menurut DailySocial.com mengatakan bahwa mobile payment di Indonesia di tahun 2007 sudah mulai terasa hal ini karena didukung oleh pihak Telkomsel mengeluarkan yang mengeluarkan $\mathrm{T}$ Cash. Tren penggunaan mobile payment di Indonesia dapat di lihat sebagai berikut : 


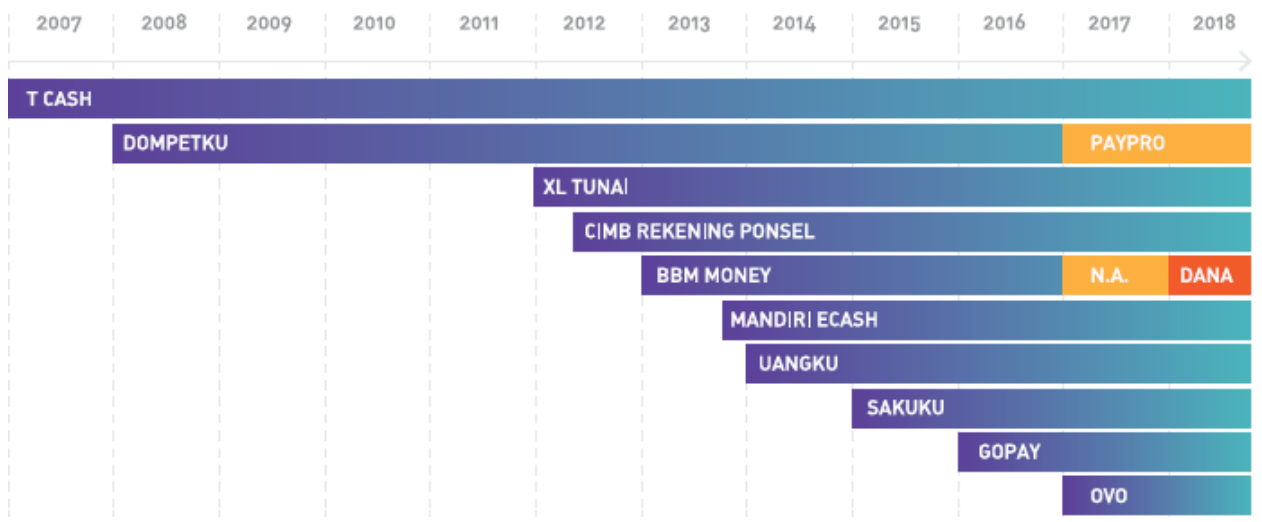

Gambar 1 Tren Mobile Payment di Indonesia

Sumber : MDI Ventures dan Mandiri Sekuritas Research

Dari gambar tersebut perkembangan mobile payment ini lah nantinya akan menggantikan penggunaan cash maupun kartu. Penggunaan teknologi server seperti pada dompet elektronik atau $e$-wallet telah menyebar dengan cepat. Hal ini didorong oleh peningkatan jumlah e-commerce di seluruh dunia mulai dari Alipay, Paypal,dan di Indonesia salah satunya adalah Gopay yang merupakan aplikasi pembayaran dalam Gojek. Sedangkan Grab menggunakan pembayaran dengan OVO untuk melakukan pembayaran via mobile. Selain untuk pembayaran, mobile payment dapat digunakan oleh konsumen untuk melakukan transaksi di berbagai merchant secara offline. Dari perubahan yang menggunakan teknologi informasi yang dikeluarkan, tidak semua masyarakat dapat mengerti dan menerima dengan pelayanan tersebut. Oleh karena itu, maka diperlukan sebagai alat ukur perilaku dari penggunanya. Dari perubahan sistem pembayaran tersebut untuk dapat mengukur perilaku pengguna teori yang paling digunakan adalah TAM (Technology Acceptance Model). Technology Acceptance Model (TAM) adalah model yang disusun oleh Davis (1989) untuk menjelaskan penerimaan teknologi yang akandigunakan oleh pengguna teknologi. Konsep TAM pada umumnya dapat membantu terutama sikap dan penerimaan seseorang pada perubahaan teknologi sehingga dapat memberikan informasi mengenai pendorong sikap individu tersebut. Konsep TAM mempunyai kajian teori yaitu minat seseorang ketika menggunakan teknologi informasi yang 
ditentukan pada faktor-faktor tertentu. Faktor tersebut antara lain adalah persepsi kemanfaatan di mana tingkat kepercayaan seseorang dengan penggunaan teknologi dapat meningkatkan kinerja. persepsi kemudahan penggunaan adalah tingkat di mana kepercayaan seseorang ketika teknologi informasi dapat menyelesaikan berbagai aktivitas pekerjaan. (Venkates dan Davis, 2000). Berdasarkan fenomena masalah tersebut maka penulis ingin mencari tahu

\section{TELAAH LITERATUR}

\section{E-Money}

Ely (1996) mengatakan bahwa e-money sebagai saldo uang yang dicatat melalui perangkat elektronik di dalam kartu "nilai tersimpan". Kartu tersebut nantinya akan disimpan melalui mikroprosesor yang dapat diisi dengan nilai uang. E-money sebenarnya dapat diciptakan oleh pemerintah ataupun perusahaan swasta. Baru-baru ini telah digunakan di banyak negara seperti Jerman, Belanda, Belgia, Singapura, dan Hong Kong. Sebuah publikasi oleh Bank for International Settlement (1996) mendefinisikan e-money sebagai nilai uang yang tersimpan atau produk prabayar di mana sejumlah uang analisis faktor dalam penggunaan mobile payment dengan TAM, maka rumusan masalah yang diperoleh adalah sebagai berikut :

1. Apakah variabel Technology Acceptance Model (TAM) memengaruhi niat pengguna pada gopay?

2. Variabel Technology Acceptance Model (TAM) apa saja yang dapat memengaruhi niat pengguna pada gopay?

disimpan di dalam media elektronik yang nantinya akan dimiliki oleh seseorang. Uang elektronik menurut Peraturan Bank Indonesia nomor 11/12 / PBI / 2009 dan 16/8 / PBI / 2014 tentang uang elektronik menyatakan bahwa uang elektronik setidaknya harus memenuhi beberapa persyaratan antara lain: (1) dikeluarkan berdasarkan jumlah uang yang disimpan kepada penerbit, (2) jumlah uang yang disimpan secara elektronik di server atau media chip, (3) digunakan sebagai alat pembayaran kepada pedagang yang bukan merupakan media penerbit, (4) ) jumlah uang yang dijalankan oleh penerbit bukan berupa tabungan yang 
diatur oleh aturan perbankan. Oleh karena itu, berdasarkan definisi tersebut, produk seperti BCA Flazz, Mandiri EMoney, atau Telkomsel Cash memenuhi kriteria e-money.

\section{Mobile Payment}

Mobile payment sekarang ini merupakan alat pembayaran dalam bentuk elektronik untuk membayar suatu tagihan, jasa dan barang. Metode pembayaran ini nantinya menggunakan perangkat telepon pengguna dengan memanfaatkan kuota internet. Dengan adanya mobile payment menyebabkan konsumen untuk beralih menggunakan transaksi non-tunai yang memiliki fungsi untuk mengefisienkan waktu dalam melakukan transaksi. Dengan adanya perangkat mobile dan koneksi internet yang bagus maka mobile payment dapat digunakan sebagat alat transaksi. Pembayaran pada bisnis yang berbasis mobile commerce ini juga bisa menggunakan mobile payment sebagai alat pembayaran, sehingga akan menimbulkan kemudahan dan kecepatan transaksi. Terdapat berbagai macam jenis layanan mobile payment yang ada baik dari perbankan maupun pengembang aplikasi. T-Cash dan Dompetku merupakan pencetus mobile payment yang berdiri sejak tahun 2007 dan 2008. Pada tahun 2012 munculah berbagai macam mobile payment yang meliputi adalah PayPro, CIMB Rekening Ponsel, XL Tunai, Dana, Uangku, Mandiri E-Cash, OVO, Gopay, dan Sakuku (Eka, 2018).

\section{Technology Acceptance Model (TAM)}

Technology Acceptance Model (TAM) diperkenalkan oleh Davis (1989) untuk mengukur penerimaan pengguna terhadap sistem informasi. Kemudian pada tahun 1989 model TAM disempurnakan. Davis et al. (1989) menyatakan bahwa tujuan TAM adalah untuk dapat memberikan maksud tentang faktor-faktor penerimaan komputer. Menurut Azjen \& Fishbein (1980) model penerimaan teknologi (TAM) diambil dari teori perilaku yang direncanakan dan teori tindakan yang beralasan. Menurut Azjen mengatakan bahwa teori psikologi sosial yang terdiri dari teori perilaku terencana dan teori tindakan beralasan Azjen \& Fishbein, 1980, TAM memberikan hubungan kausal yang terbentuk yang terdiri kepercayaansikap-niat-perilaku yang digunakan untuk mengembangkan dan memperkirakan potensi penerimaan 
pengguna teknologi. Disarankan agar orang percaya hasil potensial dari suatu tindakan sebelum mengambil keputusan dalam bentuk perilaku dengan mempertimbangkan sikap, keyakinan, dan niat seseorang. Menurut Legris et al (2003), TAM dipercaya mampu mengembangkan penggambaran yang wajar dari niat pengguna untuk menggunakan teknologi. Legris et al (2003) menunjukkan bahwa TAM adalah sangat cocok untuk memberikan model sistematis dalam menentukan tingkat penerimaan teknologi di seluruh pengguna yang dibuktikan secara empiris dengan tingkat keberhasilan $40 \%$ dalam memprediksi penggunaan sistem pengguna. Selain penelitian saat ini, dalam sebuah teori TAM sebenarnya sudah banyak manfaatnya yang dirasakan oleh pengguna terkait penggunaan sistem dan adopsi pada sistem online maupun teknologi khususnya di bidang e-money di Indonesia. Pada sebuah teori TAM setidaknya mampu memperkirakan dalam hal pengukuran adopsi konsumen dalam konteks e-commerce. Terlepas dari rentang bukti yang menunjukkan TAM sebagai model kerja yang sesuai yang digunakan untuk mendapatkan wawasan tentang penerimaan pengguna pada teknologi, Porter dan Donthu (2006) di dalam teorinya mengatakan bahwa masih ada teori lain yang dapat dimasukkan dengan menambahkan teori terkait. Topik asli oleh Akturan, dan Tezcan (2012) memasukkan manfaat yang dirasakan dan risiko yang dirasakan untuk menambahkan lebih banyak dimensi dalam adopsi teknologi oleh konsumen. Kedua variabel tersebut juga akan ditambahkan pada penelitian tentang telkomsel penggunakan pada TCash ini untuk memberikan pengetahuan yang lebih mendalam terkait penggunaan teknologi informasi. Penelitian sebelumnya yang sudah dilakukan tentang konsep e-money yang dilakukan oleh para ahli yang juga menggabungkan banyak variabelvariabel seperti risiko yang dirasakan, kepercayaan dan manfaat yang dirasakan. Oleh karena itu, sejak TAM pertama kali dikembangkan oleh Davis et al (1989) banyak model telah dimasukkan dengan menambahkan teori terkait guna mendukung dalam kajian teori. 


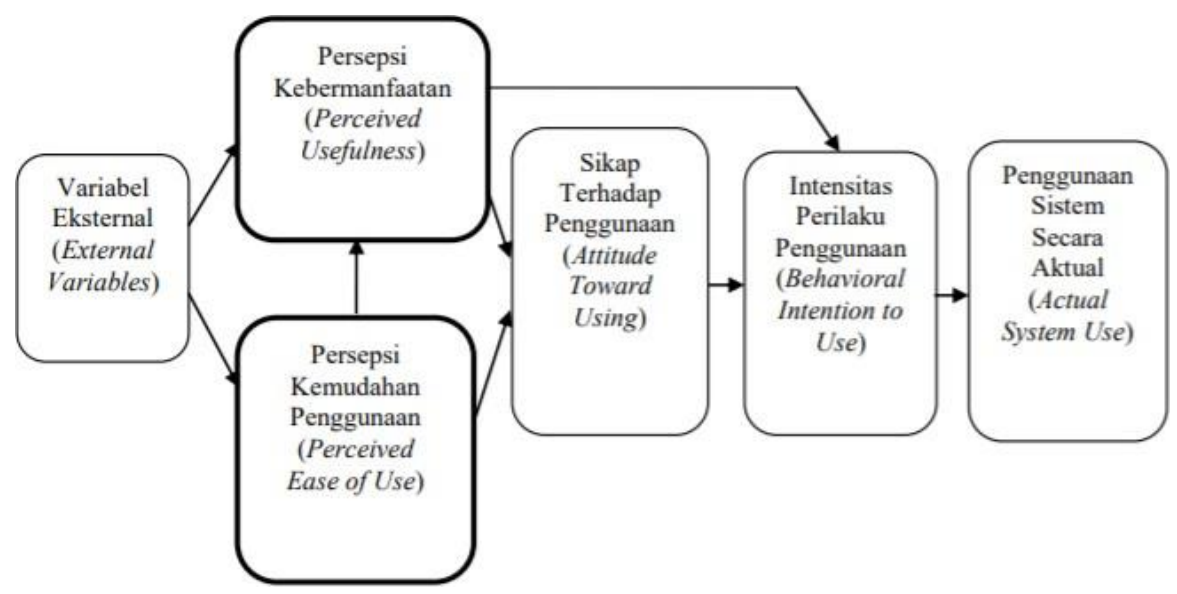

Gambar 2 Technology Acceptance Model

\section{Perceived Usefulness}

Davis et al (1989) menjelaskan manfaat yang dirasakan sebagai sejauh mana seseorang percaya bahwa menggunakan teknologi atau aplikasi baru akan meningkatkan kinerja atau produktivitas pengguna. Kegunaan juga dapat diartikan sebagai subjektif calon pengadopsi Kemungkinan bahwa penerapan teknologi baru dari sumber luar negeri akan bermanfaat bagi pribadinya dan / atau kesejahteraan perusahaan pengadopsinya (Phillips et al 1994).

\section{Perceived Ease of Use}

Perceived Ease of Use yang dirasakan didefinisikan sebagai sejauh mana seseorang percaya bahwa menggunakan teknologi baru tidak akan membutuhkan upaya fisik atau mental (Davis, 1989)

\section{Perceived risk}

Perceived risk, diperkenalkan oleh Bauer (1960), mengacu pada sifat dan jumlah risiko yang dirasakan oleh konsumen dalam merenungkan keputusan pembelian tertentu. Agaknya seorang konsumen termotivasi untuk melakukan pembelian untuk mencapai beberapa tujuan pembelian. Unsur risiko sering muncul karena sebelum melakukan pembelian, konsumen tidak selalu dapat memastikan bahwa pembelian yang direncanakan akan memungkinkan mereka mencapai tujuan pembelian mereka. Risiko yang dirasakan menurut Sitkin dan Pablo (1992) merupakan ketidakpastian yang dihasilkan dari suatu keputusan. 


\section{Perceived Benefits}

Perceived Benefits didefinisikan sebagai hasil yang meningkatkan utilitas seseorang atau memberikan nilai dengan memfasilitasi pencapaian tingkat tujuan atau nilai yang lebih tinggi (Gutman, 1982; Olshavsky 1985). Dari kesimpulan tersebut dapat dikatakan terbukti bahwa sebelum internet masuk di mata masyarakat, konsumen terlibat dalam analisis "manfaat biaya" selama proses pengambilan keputusan mereka, yang berarti bahwa ketika manfaat produk tertentu melebihi biayanya, itu akan

\section{METODOLOGI PENELITIAN}

Metodologi penelitian merupakan cara ilmiah untuk mendapatkan data sah atau dapat dikatakan valid dengan maksud dapat dikembangkan, ditemukan, dan dapat dibuktikan kebenarannya sehingga dapat digunakan untuk menjelaskan dalam hal memahami, memecahkan, dan mengantisispasi masalah Sugiyono (2014). Penelitian yang dilakukan penulis ini dilakukan dengan menggunakan metode penelitian kuantitatif. Berdasarkan jenis penelitian tersebut, penulis menggunakan jenis penelitian asosiatif yang mana lebih mungkin untuk dibeli oleh pelanggan. Selama prosedur pembelian mereka, konsumen mencari manfaat spesifik dari solusi produk dan menganggap produk sebagai bundel atribut yang memberikan manfaat (Kotler dan Armstrong, 2003). Studi terbaru oleh Kim et al (2008) menyatakan bahwa sebelum konsumen membeli suatu produk, ia mengevaluasi evaluasi kognitif dan afektif dari manfaat hedonistik dan utilitarian. Konsumen menilai nilai produk dengan mengevaluasi pengorbanan yang dirasakan dan manfaat yang dirasakan

penelitian yang bertujuan untuk mengetahui pengaruh ataupun hubungan antara dua variabel atau lebih. Sedangkan, penelitian deskriptif dilakukan untuk mengetahui nilai variabel mandiri, baik satu variabel atau lebih (independen) tanpa membuat perbandingan, atau menghubungkan dengan variabel yang lain. Dari penelitian asosiatif tersebutlah nantinya akan dilakukan untuk dapat mencari tahu variabel- variabel pada TAM mulai dari persepsi kemudahan (perceived ease of use), persepsi kegunaan (perceived usefullness) dan sikap 
terhadap penggunaan (attitude toward using) yang secara implisit terhadap keinginan untuk menggunakan niat pengguna pada mobile payment. Penulis menambahkan dengan metode penelitian kuantitatif dekriptif dengan menggunakan deskriptif statistik untuk mengetahui faktor apa saja yang mempengaruhi penggunaan masingmasing mobile payment pada gopay. Pengumpulan data dilakukan dengan menggunakan berdasarkan sumber baik sumber primer maupun sekunder. Data primer didapatkan dari penyebaran hasil kuesioner kepada pengguna gopay baik yang ada di Jakarta maupun di Tangerang. Sedangkan data sekunder yang digunakan oleh penulis kajian litertatur penelitian sebelumnya mulai dari jurnal, buku dan lain sebagainya untuk mencari kebenaran dalam suatu fenomena. Penyebaran kueisoner pun kepada responden harus memiliki kriteria sebagai pengguna gopay dan sebaran pun dilakukan di wilayah Jakarta dan Tangerang. Untuk dapat menyelesaikan penelitian tersebut penulis menyusun dengan menggunakan skala Likert. Skala likert merupakan suatu skala untuk mengukur sikap, pendapat dan persepsi seseorang atau sekelompok orang tentang fenomena sosial. Dari penyebaran kuesioner dengan menggunakan skala Likert nantinya responden memilih jawaban yang diberi skor yang sudah diberikan suatu pernyataan untuk mendukung jawaban tersebut atau jawaban yang sudah dipilih. Penulis untuk menyelesaikan penelitian ini menggunakan teknik sampling yang digunakan adalah non probability sampling dan incidental sampling yaitu di mana mengambil sampel untuk dijadikan penelitian dengan ketersediaan elemen dan kemudahan untuk mendapatkannya. Sampel yang nantinya diambil merupakan sampel yang mana responden ada pada tempat dan waktu yang tepat. Penulis mengambil sampel dari jumlah penduduk yang ada di Jakarta dan Tangerang yang menggunakan gopay. Sedangkan untuk teknik non-probability sampling, penulis menggunakan rumusan dasar untuk mengetahui ukuran sampel dengan populasi yang tidak di ketahui. Sehingga dari rumusan tersebut penulis menentukan jumlah sampel yang untuk dilakukan penelitian di mana minimal yang harus digunakan untuk menjalankan penelitian adalah sebanyak 50 responden, dengan artian responden tersebut adalah adalah 
sebanyak 50 orang pengguna gopay. Penulis menggunakan metode faktor analisis yang di mana faktor analisis tersebut digunakan untuk mengetahui faktor apa saja yang dapat menimbulkan niat pengguna pada gopay dan bisa dilihat dari nilai-nilai tersebut untuk mencari faktor apa yang palig mempengaruhi penggunaan gopay dari faktor yang nantinya akan di analisis. Dalam pengolahan tersebut penulis menggunakan program yang di bantu dengan program SPSS Statistics versi 20 untuk mengolah data yang didapatkan dari kuisioner agar dapat dianalisis lebih lanjut.

\section{HASIL DAN PEMBAHASAN}

Tabel 2 Uji Barlett dan Kaiser-Meyer-Olkin Gopay

\begin{tabular}{ccc}
\multicolumn{3}{c}{ KMO and Bartlett's Test } \\
Kaiser-Meyer-Olkin Measure of Sampling &, 774 \\
& Adequacy. & \\
Bartlett's Test & Approx. Chi-Square & 369,711 \\
of Sphericity & Df & 45 \\
& Sig. &, 000 \\
\hline
\end{tabular}

Berdasarkan tabel diatas dapat diketahui di mana data yang sudah di analisa dengan bantuan SPPS Statistics memiliki nilai KMO atau KaiserMeyer-Olkin Measure of Sampling Adequacy sebesar 0,774 artinya hal ini menunjukkan bahwa data yang digunakan sangat baik untuk uji analisis faktor, sedangkan untuk nilai Barlett Test of Sphericity sebesar 0,000 $(0,000$ $<0,05)$ sehingga dapat dikatakan bahwa penelitian tersebut sudah memenuhi syarat bahwa model faktor yang terbentuk layak untuk digunakan. 


\begin{tabular}{ccc} 
Tabel 3 Uji Measure of Sampling Adequacy (MSA) \\
\multicolumn{3}{c}{ Communalities } \\
& Initial & Extraction \\
Applicable & 1.000 & .675 \\
Flexible & 1.000 & .726 \\
Controlable & 1.000 & .754 \\
Effectiveness & 1.000 & .899 \\
Usefulness & 1.000 & .738 \\
Benefits & 1.000 & .851 \\
Compatibility & 1.000 & .655 \\
\hline
\end{tabular}

Uji Measure of Sampling Adequacy (MSA)

Dasar pengambilan keputusan untuk uji ini antara lain sebagai berikut :

- Nilai MSA > 0.5, maka faktor layak untuk digunakan.

- Nilai MSA $<0.5$, maka faktor tidak layak untuk digunakan.
Berdasarkan hasil analisa diatas, maka dapat diberi kesimpulan bahwa semua faktor yang sudah digunakan dalam penelitian tersebut memiliki nilai MSA Measure of Sampling Adequacy > 0,5 sehingga dengan demikian dapat dikatakan semua faktor layak untuk digunakan.

Tabel 4 Rotated Component Matrix

\begin{tabular}{cc}
\multicolumn{2}{c}{ Component Matrix } \\
& Component \\
& 1 \\
Applicable & .810 \\
Flexible & .802 \\
Controlable & .757 \\
Effectiveness & .790 \\
Usefulness & .799 \\
Benefits & .727 \\
Compatibility & .829 \\
Recommendation & .812 \\
Reuse_Intention & .788 \\
Pay_More & .638 \\
Extraction Method: Principal \\
Component Analysis \\
a. 1 components extracted \\
\hline
\end{tabular}


Berdasarkan tabel diatas, dapat disimpulkan bahwa seluruh faktor tergabung di dalam satu komponen, yaitu TAM. Selain itu, kita dapat juga menyimpulkan bahwa faktor yang paling mempengaruhi intention to use gopay adalah faktor effectiveness dengan nilai 0,790. Faktor yang kedua yang mempengaruhi intention to use gopay adalah Applicable dengan nilai yang tidak jauh berbeda dengan faktor Effectiveness, yaitu 0,810. Faktor ketiga yang dapat mempengaruhi intention to use gopay adalah faktor benefits dengan nilai 0,727 . Berdasarkan hasil pre-test dan jurnal yang dipelajari oleh penulis, terdapat 10 faktor yang

mempengaruhi keinginan untuk menggunakan gopay. 10 faktor tersebut adalah Applicable, Flexible, $\quad$ Controlable, Effectiveness, Usefulness, Benefits, Compatibility, Recommendation, Reuse Intention, dan Pay More. Bisa dilihat dari hasil analisis fakor sebelumnya yang menunjukkan bahwa semua faktor ini berada dalam satu kelompok TAM dan tidak membentuk faktor baru yang artinya, secara keseluruhan semua faktor TAM yang digunakan dalam penelitian ini mempengaruhi keinginan menggunakan gopay. Jika hasil analisis faktor tersebut di urutkan, berikut adalah ranking penilaiannya :

Tabel 5 faktor yang paling mempengaruhi

\begin{tabular}{lcc} 
Rank & Factor & Value \\
1 & Compatibility & .829 \\
2 & Recommendation & .812 \\
3 & Applicable & .810 \\
4 & Flexible & .802 \\
5 & Usefulness & .799 \\
6 & Effectiveness & .790 \\
7 & Usefulness & .799 \\
8 & Reuse Intention & .788 \\
9 & Controlable & .757 \\
10 & Pay_More & .638 \\
\hline
\end{tabular}


Faktor yang paling mempengaruhi keinginan untuk menggunakan gopay adalah Compatibility, Recommendation, Applicable, Flexible. Compatibility menunjukkan bahwa aplikasi gopay mampu membantu pengguna untuk mencapai tujuan dalam melakukan transaksi dimana dalam hal ini, sangat sederhana yaitu pengguna dapat melakukan pembayaran dengan aplikasi gopay. Selain itu, compatibility juga menunjukkan bahwa aplikasi gopay menjadi recommendation yang dapat digunakan oleh pengguna sebagai alat pembayaran yang artinya mungkin saja pengguna tidak menjadikan aplikasi gopay sebagai alat pembayaran utama mereka ketika sedang berbelanja, namun mereka tetap mau menggunakannya dan juga aplikasi ini dikatakan efektif karena mampu membantu mempercepat proses transaksi. Pengguna tidak perlu mengeluarkan dompet mereka dan memberikan kartu mereka untuk digunakan pada mesin EDC. Kini, pengguna hanya perlu membawa smartphone dan mereka bisa melakukan pembayaran dimana mempercepat proses transaksi mereka. Selain karena efektivitasnya, pengguna mau menggunakan gopay karena applicable yang artinya aplikasi gopay mudah dipahami dan digunakan oleh penggunanya serta dapat digunakan dalam kehidupan sehari-hari. Flexible dari gopay sendiri memang terlihat sangat simple dan mudah untuk dipahami. Faktor ketiga yang sangat mempengaruhi keinginan penggunaan gopay adalah karena benefits yang ditawarkan. Aplikasi gopay memberikan keuntungan melalui kenyamanan dalam melakukan transaksi, keuntungan melalui banyaknya promosi dan banyaknya kerjasama dengan merchant yang menjadikan pengguna merasa convenient untuk menggunakan gopay. Sedangkan, faktor yang memiliki pengaruh paling rendah terhadap gopay adalah reuse intention, controllable dan pay more. Hal ini merujuka pada pengguna gopay tidak terlalu ingin menggunakannya secara bekala atau apabila ada perubahan dalam aplikasi gopay itu sendiri, penguna gopay mungkin tidak terlalu ingin menggunakannya, Bagi para pelaku bisnis yang khususnya bergerak di bidang FMCG atau makanan dan minuman, mungkin bisa mempertimbangkan untuk bermitra dengan gopay karena sudah terbukti 
gopay memberikan kemudahan bagi para pengguna dalam melakukan pembayaran, Selain itu, bagi pihak gopay sendiri bisa mengembangkan fitur atau tampilan yang dapat mempermudah pengguna dalam melakukan transaksi. Terlebih lagi, gopay memiliki fitur-fitur baru seperti kemampuan dari aplikasi tersebut untuk transfer saldo kepada sesama pengguna, pembayaran-pembayaran untuk tagihan-

\section{SIMPULAN DAN SARAN}

Berdasarkan penelitian diatas, maka penulis memberikan kesimpulan dan saran, adapun kesimpulan dan saran yang dimaksud antara lain: dapat:

1. faktor yang mempengaruhi niat pengguna pada gopay mulai dari applicable, flexible, controllable, effectiveness, usefulness, Benefits, compatibility, recommendation, reuse intention, dan pay more dinyatakan tidak ditemukan adanya faktor baru pada niat penggunaaan gopay sehingga dari penelitian tersebut dapat disimpulkan bahwa faktor TAM merupakan saling ketergantungan antara satu tagihan listrik, BPJS, atau pulsa, dan juga kemudahan dalam membayar dengan penggunaan scan barcode maupun juga dengan menggunakan alat yang disediakan khusus untuk gopay bertransaksi langsung ke smartphone pengguna. gopay juga sekarang mempunyai fitur dimana kita dapat membeli atau membayar menggunakan gopay tetapi pembayaran akan diproses pada akhir bulannya.

dengan yang lain yang dapat memengaruhi niat penggunaan pada gopay.

2. Faktor yang paling mempengaruhi niat pengguna pada gopay mulai dari benefits, controlable dan effectivenesss. Sedangkan untuk ada beberapa faktor yang mempunyai pengaruh yang paling kecil terhadap niat pengguna pada gopay antara lain usefulness, reuse intention, dan pay more. 
Saran

Berdasarakan yang dilakukan penulis dalam melakukan penelitian, maka ada beberapa saran yang penulis sampaikan diantaranya saran nya sebagai berikut:

1. Untuk meningkatkan keinginan penggunaan pada gopay, seharusnya pihak gopay perlu mengembangkan aplikasinya untuk dapat mempercepat dan mempermudah proses transaksi, muali dari pembayaran dengan menggunakan barcode dan juga memberikan suatu kemudahan untuk top-up, seperti bekerja sama dengan mini market ataupun dengan perbankan untuk menambah saldo gopay, atau dapat pula dengan cara bekerjasama dengan market place atau e-commerce untuk melakukan pembayaran dengan gopay sehingga mempermudah pengguna gopay untuk berbelanja melalui platform tertentu. Pada saat ini pengguna untuk melakukan pembayaran di market place masih harus menggunakan virual account perbankan dan membuat mereka harus membuka dua aplikasi pada saat berbelanja, kedepannya pihak gopay memiliki suatu sistem yang mana para pengguna dapat berbelanja dan melakukan pembayaran melalui satu aplikasi saja yang nantinya akan terhubung dengan pembayaran lainnya sehingga hal ini tentu saja akan sangat memudahkan proses transaksi pembayaran dan membuat pengguna gopay untuk tetap setia menggunakannya meskipun selain gopay masih ada lagi aplikasi yang bersaing dengan banyak program promosi yang ditawarkan.

2. Untuk meningkatkan niat pengguna pada penggunaan gopay sebaiknya menggunakan promosi-promosi yang dapat menarik para pengguna baik itu pengguna baru maupun pengguna lama untuk tetap menggunakan gopay meskipun jika ada perubahan pada aplikasi gopay diharapkan nantina pengguna mendapatkan point yang mana point tersebut dipindahkan ke dalam saldo gopay, atau dapat dibelanjakan kembali dengan memberikan 
promosi yang lebih menarik yang dapat di beli dari gopay.

Selain memberikan poin, sebaiknya gopay dapat mengadakan program pemberian ranking terhadap setiap pengguna gopay baik itu pengguna menggunakan go-ride, go-food atau berbagai aktivitas layanan lainnya, pengguna gopay akan mendapatkan voucher gratis mulai dari voucher makan, transportasi online atau bahkan pengiriman barang yang diberikan secara teratur. Gopay pun dapat membuat program keanggotaan yang mana program

\section{DAFTAR PUSTAKA}

Ajzen, L \& Fishbein, M (1980).

Understanding attitude and predicting social behavior. Englewood Cliffs, NJ: PrenticeHall.

Akturan, U \& Tezcan, N (2012). Mobile banking Adoption Of The Youth Market. Marketing Intelligence \& Planning, Vol 30 No. 4

Amstrong, dan Kotler 2003, Dasar- keanggotaan tersebut bersifat cukup mengikat pengguna utuk terus menggunakan gopay bagi mereka yang setia menggunakan gopay dengan membagikan kedalam segmentasi tertentu misalnya seperti keanggotaan silver, keanggotaan gold, dan keanggotaan platinum yang pada akhirnya dari keanggotaan tersebut akan memiliki manfaat yang berbeda-beda, sehingga tentu saja nantinya akan semakin tinggi tingkatannya akan semakin banyak pula keuntungan yang didapat.

dasar Pemasaran, Jilid 1, Edisi Kesembilan. Penerbit PT. Indeks Gramedia, Jakarta

Bauer, R. A. (1960). Consumer

Behavior as Risk Taking. Journal of Business Research, 23-33. 
Davis, F. D. 1989. Perceived usefulness, perceived ease of use, and user acceptance of information technology. MIS Quarterly. Vol. 13 No. 3. h. 31940.

Ely, B. (1996). Electronic money and monetary policy: Separating fact from fiction. The Futureof Money in the Information Age, CATO Institute's 14th Annual Monetary Conference. 23 May 1996. Retrieved from http://www.cato.org/ moneyconf/14mc-2.ht ml

Guttman, J. (1982). A Mean-End Chain Model Based On Cunsumer Categorization Processes. Journal Marketing, 46 (Spring), 60-72

Legris, P., John I \& Collerette, P. (2003) Why do people use information technology?.Information and Management Journal, Vol 40

Kim et al. (2008), Customers

Cognitive, Emotional, and Actionable Response to the Servicescape: A Test of the Moderating Effect of theRestaurant Type. International Journal of Hospitality Management
Olshavsky, Richard W. (1985).

Toward A More
Comprenhensive Theory of
Choice, in Advances in
Consumer Research, Elizabeth
C. Hirschman and Morris
Holbrook (eds.) 12. Pp. 465-470

Porter, C, E \& Donthu, N. (2006).

Using the technology acceptance model to explain how attitudes determine Internet usage: The role of perceived access barriers and demographics. Journal of Business Research 59. 9991007

Sitkin, S.B., \& Pablo, A.L. 1992.

Reconceptualizing the determinants of risk behavior. Academy of Management Review, 17: 9-38.

Sugiyono. (2014). Metode Penelitian Pendidikan Pendekatan Kuantitatif, Kualitatif, dan $R \& D$. Bandung: Alfabeta

Venkatesh, V. dan Davis, F.D. 2000. A Theoretical Extension of the Technology Acceptance Model: Four Longitudinal Field Studies. Management Science, 46 (2), pp. 186-204. 